\title{
Dental sedation by anesthesiologists or dentists: a view from Turkey
}

\author{
Berrin Isik ${ }^{1}$, Mustafa Arslan ${ }^{1 *}$, Mustafa Sancar Atac ${ }^{2}$, Ergun Yucel $^{2}$
}

\begin{abstract}
Background: Except for conscious sedation (with nitrous oxide/oxygen), sedation of the dental patient has been applied by anesthesiologists in Turkey. But little is known about anesthesiology and reanimation specialist (ARS)'s and dental medical doctor (DMD)'s views about who should manage the dental sedation. Using a survey, Turkish ARSs' and DMDs' opinions regarding sedation of dental patients are examined.

Methods: A questionnaire was conducted to ARS and DMD participants that are active in clinical practices in Turkey. The questionnaire consists of 5 point Likert Scale which contains the options; strongly disagree (1), disagree (2), unsure (3), agree (4), strongly agree (5), and it aims to evaluate the perceptions of ARS and DMD participants, about 11 statements in relation to dental sedation which is performed by DMDs. The data was analyzed by SPSS 12.00 version for windows, and descriptive statistics was used.

Results: From 200 ARSs and 200 DMDs, a total of 400 questionnaires were obtained. The findings reveal that except for $4.5 \%$, most of the ARSs had performed sedation or general anesthesia for dental treatment rarely or never, and half of the ARSs strongly disagreed with the statement that DMDs can provide moderate sedation during dental treatment. $10.5 \%$ of the ARSs strongly agreed, and $24 \%$ agreed, while $39.5 \%$ of DMDs strongly agreed, and $60.5 \%$ agreed with the statement "If dentists were trained to provide moderate sedation in the dental office, there would be less referral for dental treatment under general anesthesia".

Conclusions: Many ARSs in Turkey do not perform sedation of dental patients, but they suspect that DMDs are able to do it. Sedation applications for dental treatments are real necessities for handicapped or anxious patients and children. Guidelines for education and sedation management should be presented to clarify who should be in charge of managing sedation of dental patients.
\end{abstract}

Key words: Sedation, Survey, Dental treatment

\section{Introduction}

Accomplishment of dental treatment under sedation increases comfort of patients and dentists. Vasovagal reactions are less likely to occur if anxiety and fear can be controlled by sedation. Compared to application of local anesthesia alone, sedation together with local anesthesia may lead to serious complications such as respiratory depression. Potent general anesthetics, inhalational agents, sedatives, and opioids have the potential to depress respiratory function. Minimal or moderate sedation carries no serious side effects, if appropriate safe doses of anesthetics and monitorization technique are chosen. On the other hand, patient's intended level of minimal to moderate sedation carries possibility to drop into deep sedation or general anesthesia. General anesthesia or deep sedation has much more risks than conscious sedation, and deep sedation practices requires more training (1-5). Therefore, the health professional, who is in charge of performing dental sedation, must be clarified. At this point, the opinions of ARSs and DMDs become significant.

Anesthesiology and reanimation specialty is a branch of medical science. After completing medical school, physicians, to become a medical specialist in Turkey, further have to continue their medical education in anesthesiology and reanimation by completing 4 years of residency. General anesthesia and sedation (except conscious sedation with nitrous oxide/oxygen) are performed by only ARSs in Turkey. ARSs are primarily in charge of general anesthesia in medical patients and they are also responsible from sedation for imaging and procedural interventional purposes. Procedural sedation for dental treatment is also delivered by ARSs (6). Although full time working ARSs at dental office are not common; phobic, medically compromised, handicapped patients or discordant children may need sedation or general anesthesia during dental treatment $(1,7-10)$. 
There are some regions where ARSs are the sole providers of sedation practices in surgery units. There are also countries in which there are a few trained non-anesthesiologists who provide sedation in specified circumstances and locations, and in others, there are a number of non-physician professionals who provide sedation in diverse settings $(1,7-10)$. The related legislation in Turkey allows dentists to perform only conscious sedation with $\mathrm{N}_{2} \mathrm{O}(40 \%) / \mathrm{O}_{2}$ $(60 \%)$.

Skills and practice standards in procedural sedation are a debated issue $(1,7-12)$. It is argued that insufficient number of ARSs influences the availability of sedation services. According to American Society of Anesthesiologinions of the participants about dentist-performed sedation were explored through 11 statements, each with 5 possible Likert Scale responses: strongly disagree (Score 1), disagree (Score 2), unsure (Score 3), agree (Score 4), and strongly agree (Score 5).

$0 \%$ of the respondents. The total number of sedations and general anesthetics administered for the year was 115,940 . In this survey, midazolam, fentanyl, diazepam, metohexital, propofol, ketamine, meperidine, nalbufin and thiopental were administered as IV anesthetics. The results of the survey showed that, for the 10-year period, 30 patients required to be transferred to the hospital 2 mortalities and two cases of long-term morbidity occurred.

Most practitioners recognize the importance of dental anesthesia education and training. However, there is a little consensus regarding the extent of anesthesia training that is appropriate for a dental school's pre-doctoral curriculum $(15,20,21)$. Moore et al. presented the findings about preparedness and experiences with dental anesthesia of dental school graduates, in which they reported being least prepared in oral/intravenous sedation, and general anesthesia (20). For graduates currently in general practice, those who had participated in the anesthesia selective program reported being better prepared in most subjects relating to anesthesia and patient care. They reported that advanced training and increased clinical experiences in anesthesia may also be an effective means to better prepare graduates to assess medical histories, to manage medical emergencies, and to be willing to treat medically complex patients as well as patients with special health care needs.

Hicks et al. described what training programs in pediatric dentistry and dental anesthesiology were doing to meet future needs for deep sedation/general anesthesia services required for pediatric dentistry (11). Residency directors from 10 dental anesthesiology training programs in North America and 79 directors from pediatric dentistry training programs in North America were asked to answer an 18-item and 22-item online survey. Dental anesthesiology directors compared to 2, 5, and 10 years ago have seen an increase in the requests for dentist anesthesiologist services by pediatric dentists reported by $56 \%$ of respondents (past 2 years), $63 \%$ of respondents (past 5 years), and $88 \%$ of respondents (past 10 years), respectively. Predicting the future need of dentist anesthesiologists is an uncertain task, but these results show pediatric dentistry directors and dental anesthesiology directors are considering the need, and they recognize a trend of increased need for dentist anesthesiologist services over the past decade.

American Dental Association (ADA)'s guidelines for teaching pain control and sedation to dentists and dental student recommends that the predoctoral dental curriculum should provide the knowledge and skills necessary to competently administer minimal sedation to alleviate dental anxiety and to provide effective pain control (22).

For graduated DMDs from the university who prefer to go further education in oral and maxillofacial surgery specialty, have to complete the rotation program for three months in anesthesiology department in Turkey. In this period; specialty students are trained about general anesthesia, sedation and cardiopulmonary resuscitation and students are permitted to take elective courses about sedation as well.

On the other hand, for the basic dental students and for other specialties except oral and maxillofacial surgery, "anesthesiology rotation" is not covered by the compulsory courses.

\section{Conclusion}

Patients with dental fear or anxiety or medical compromises require sedation. Substantially minimal and moderate sedation during dental treatment can be performed by DMDs. But, minimal moderate or deep sedation are only terminological state. Patient's intended level of minimal to moderate sedation carries possibility to drop into deep sedation or general anesthesia. DMDs who apply sedation technique must be trained to manage the airway, insert an IV line and intubate a patient properly.

Furthermore, DMDs who administer sedation must be trained about basic and advanced life support

\section{Acknowledgement}

All authors state that there is no conflict of interest 
Table 1: Opinions of the ARSs and DMDs about dental sedation procedures n (\%)

\begin{tabular}{|c|c|c|c|c|c|c|c|}
\hline & $n=200+200$ & $\begin{array}{l}\text { Strongly } \\
\text { Disagree } \\
\mathbf{n} \%\end{array}$ & $\begin{array}{c}\text { Disagree } \\
\mathbf{n} \%\end{array}$ & $\begin{array}{c}\text { Unsure } \\
\text { n\% }\end{array}$ & $\begin{array}{l}\text { Agree } \\
\mathbf{n} \%\end{array}$ & $\begin{array}{c}\text { Strongly } \\
\text { Agree } \\
\mathbf{n} \%\end{array}$ & $\mathbf{p}$ \\
\hline \multirow{2}{*}{$\begin{array}{l}\text { DMDs are able to provide } \\
\text { moderate sedation in the dental } \\
\text { office }\end{array}$} & ARS (200) & $100(50)$ & $32(16)$ & $36(18)$ & $32(16)$ & 0 & \multirow{2}{*}{$\begin{array}{c}\mathrm{X}^{2}=150.020 \\
\mathrm{p}<0.0001\end{array}$} \\
\hline & DMD (200) & $7(3.5)$ & $14(7)$ & $56(28)$ & $101(50.5)$ & $22(11)$ & \\
\hline \multirow{2}{*}{$\begin{array}{l}\text { In the DMDs office, moderate } \\
\text { sedation should be provided by } \\
\text { medical anesthesiologists }\end{array}$} & ARS (200) & 0 & $32(16)$ & 0 & $68(34)$ & $100(50)$ & \multirow{2}{*}{$\begin{array}{c}\mathrm{X}^{2}=135.295 \\
\mathrm{p}<0.0001\end{array}$} \\
\hline & DMD (200) & $15(7.5)$ & $80(40)$ & $42(21)$ & $42(21)$ & $21(10.5)$ & \\
\hline \multirow{2}{*}{$\begin{array}{l}\text { Moderate sedation should be } \\
\text { provided in a hospital setting }\end{array}$} & ARS (200) & $3(1.5)$ & $3(1.5)$ & $28(14)$ & $115(57.6)$ & $51(25.5)$ & \multirow{2}{*}{$\begin{array}{c}\mathrm{X}^{2}=259.987 \\
\mathrm{p}<0.0001\end{array}$} \\
\hline & DMD (200) & $29(14.5)$ & $120(60)$ & $30(15)$ & 0 & $21(10.5)$ & \\
\hline \multirow{2}{*}{$\begin{array}{l}\text { DMDs are able to provide oral } \\
\text { sedation }\end{array}$} & ARS (200) & $21(10.5)$ & $86(43)$ & $26(13)$ & $54(27)$ & $13(6.5)$ & \multirow{2}{*}{$\begin{array}{c}\mathrm{X}^{2}=129.617 \\
\mathrm{p}<0.0001\end{array}$} \\
\hline & DMD (200) & 0 & $7(3.5)$ & $28(14)$ & $135(67.5)$ & $30(15)$ & \\
\hline \multirow{2}{*}{$\begin{array}{l}\text { DMDs are able to provide basic } \\
\text { life support in an emergency } \\
\text { situation }\end{array}$} & ARS (200) & $13(6.5)$ & $10(5)$ & $30(15)$ & $106(53)$ & $41(20.5)$ & \multirow{2}{*}{$\begin{array}{c}\mathrm{X}^{2}=4.674 \\
\mathrm{p}=0.322\end{array}$} \\
\hline & DMD (200) & $5(2.5)$ & $7(3.5)$ & $35(17.5)$ & $108(54)$ & $45(22.5)$ & \\
\hline \multirow{2}{*}{$\begin{array}{l}\text { Oral sedation is a safe procedure } \\
\text { for other practices such as } \\
\text { radiological clinics }\end{array}$} & ARS (200) & $13(6.5)$ & $57(28.5)$ & $23(11.5)$ & $87(43.5)$ & $20(10)$ & \multirow{2}{*}{$\begin{array}{c}\mathrm{X}^{2}=27.780 \\
\mathrm{p}<0.0001\end{array}$} \\
\hline & $\operatorname{DMD}(\mathrm{n}=193)$ & $14(7.3)$ & $21(10.9)$ & $50(25.9)$ & $81(42)$ & $27(14)$ & \\
\hline \multirow{2}{*}{$\begin{array}{l}\text { A 96-h programs sufficient to } \\
\text { enable a DMDs to provide } \\
\text { inhalational sedation with nitrous } \\
\text { oxide and oxygen at his/her office }\end{array}$} & ARS (200) & $21(10.5)$ & $95(47.5)$ & $68(34)$ & $16(8)$ & 0 & \multirow{2}{*}{$\begin{array}{c}\mathrm{X}^{2}=158.396 \\
\mathrm{p}<0.0001\end{array}$} \\
\hline & DMD (200) & 0 & $14(7)$ & $71(35.5)$ & $85(42.5)$ & $30(15)$ & \\
\hline \multirow{2}{*}{$\begin{array}{l}\text { DMDs can provide oral chloral } \\
\text { hydrate sedation for ASA } 1 \\
\text { children }\end{array}$} & ARS (200) & 0 & $75(35.5)$ & $53(26.5)$ & $52(26)$ & $20(10)$ & \multirow{2}{*}{$\begin{array}{c}\mathrm{X}^{2}=49.583 \\
\mathrm{p}<0.0001\end{array}$} \\
\hline & DMD (200) & 0 & $21(10.5)$ & $50(25)$ & $107(53.5)$ & $22(11)$ & \\
\hline \multirow{2}{*}{$\begin{array}{l}\text { DMDs can provide oral midazolam } \\
\text { sedation for ASA } 1 \text { children }\end{array}$} & ARS (200) & 0 & $112(56)$ & $37(18.5)$ & $51(25.5)$ & 0 & \multirow{2}{*}{$\begin{array}{c}\mathrm{X}^{2}=85.903 \\
\mathrm{p}<0.0001\end{array}$} \\
\hline & DMD (200 & 0 & $28(14)$ & $49(24.5)$ & $112(56)$ & $11(5.5)$ & \\
\hline \multirow{2}{*}{$\begin{array}{l}\text { General anesthesia is the first } \\
\text { choice for dental treatment of } \\
\text { patients that do not cooperate with } \\
\text { nonpharmacological behavior } \\
\text { management methods }\end{array}$} & ARS (200) & $32(16)$ & $78(39)$ & $32(16)$ & $21(10.5)$ & $37(18.5)$ & \multirow{2}{*}{$\begin{aligned} X^{2} & =115.756 \\
p & <0.0001\end{aligned}$} \\
\hline & DMD (200) & 0 & $31(15.5)$ & $28(14)$ & $112(56)$ & $29(14.5)$ & \\
\hline \multirow{2}{*}{$\begin{array}{l}\text { If DMDs were trained to provide } \\
\text { moderate sedation in the dental } \\
\text { office there would be less referral } \\
\text { for dental treatment under general } \\
\text { anesthesia }\end{array}$} & ARS (200) & $42(21)$ & 89 (44.5) & 0 & $48(24)$ & $21(10.5)$ & \multirow{2}{*}{$\begin{array}{c}X^{2}=196.173 \\
p<0.0001\end{array}$} \\
\hline & DMD (200) & 0 & 0 & 0 & $121(60.5)$ & $79(39.5)$ & \\
\hline
\end{tabular}

*Anesthesiology and Reanimation Specialist (ARS), **Dental Medical Doctor (DMD)

\section{References}

1- Marks LA, Martens LA. Pharmacologic sedation in dentistry: an overview. Rev Belge Med Dent. 2003;58(4):245-56.

2- Gozal D, Gozal Y. Pediatric sedation/anesthesia outside the operating room. Curr Opin Anaesthesiol 2008;21:494-8.

3- An Updated Report by the American Society of Anesthesiologists Task Force on Sedation and Analgesia by Non-Anesthesiologists Practice Guidelines for Sedation and Analgesia by Non-Anesthesiologists Anesthesiology 2002;96:1004-17.

4- Krauss B, Green SM. Procedural sedation and analgesia in children. Lancet 2006;367:766-80.

5- Becker DE, Haas DA. Management of complications during moderate and deep sedation: respiratory and cardiovascular considerations. Anesth Prog. 2007;54(2):5968 .

6- Günerli A. Professional and Legal Responsibilities of Anaesthesiologists, Legal Decrees, Relevant Legislation and Bylaws J Turk Anaesth Int Care 2009; 37(6):333-349.
7- $\quad$ Chanpong B, Haas DA, Locker D. Need and demand for sedation or general anesthesia in dentistry: a national survey of the Canadian population. Anesth Prog 2005;52:3-11.

8- Costa PS, Valadao WJ Jr, Costa LR. Dental sedation by dentists: a view from anesthesiologists working in central Western Brazil. Anesth Analg. 2010:1;110(1):110-4.

9- Allen SC, Bernat JE, Perinpanayagam MK. Survey of sedation techniques used among pediatric dentists in New York State. N Y State Dent J. 2006;72(5):53-5.

10- Paterson SA, Tahmassebi JF. Paediatric dentistry in the new millennium: Use of inhalation sedation in paediatric dentistry. Dent Update. 2003;30(7):350-6, 358.

11- Hicks CG, Jones JE, Saxen MA, Maupome G, Sanders BJ, Walker LA, Weddell JA, Tomlin A. Demand in pediatric dentistry for sedation and general anesthesia by dentist anesthesiologists: a survey of directors of dentist anesthesiologist and pediatric dentistry residencies. Anesth Prog. 2012;59(1):3-11.

12- Allen SC, Bernat JE, Perinpanayagam MK. Survey of Sedation Techniques used Among Pediatric Dentists in New York State. N Y State Dent J. 2006;72(5):53-5. 
13- ASA guidelines: Basic Anesthetic Monitoring http://www.asahq.org/For-Members/Standards-Guidelinesand-Statements.

14- ASA Guidelines: Continuum Depth of Sedation http://www.asahq.org/For-Members/Standards-andGuidelines.

15- American Academy of Pediatric Dentistry. Guidelines on use of anesthesia personnel in the administration of officebased deep sedation/general anesthesia to the pediatric dental patient. Reference Manual. 2009-10;31(6):169-171.

16- Hallonsten A.L., Jensen B., Raadal M., Veerkamp J., Hosey M.T., Poulsen S.. EAPD European Academy of Paediatric Dentistry: Guidelines on Sedation in Paediatric Dentistry. http://www.eapd.gr/dat/5CF03741/file.pdf.

17- Boynes SG, Moore PA, Tan PM Jr, Zovko J. Practice characteristics among dental anesthesia providers in the United States. Anesth Prog. 2010;57(2):52-8.
18

Olabi NF, Jones JE, Saxen MA, Sanders BJ, Walker LA, Weddell JA, Schrader SM, Tomlin AM. The use of officebased sedation and general anesthesia by board certified pediatric dentists practicing in the United States. Anesth Prog. 2012;59(1):12-7.

19- Flick WG, Katsnelson A, Alstrom H. Illinois dental anesthesia and sedation survey for 2006. Anesth Prog. 2007;54(2):52-8

20- Moore PA, Boynes SG, Cuddy MA, Giovannitti JA Jr, Zovko J. Educational experiences and preparedness in dental anesthesia: five-year outcome assessment and conclusions. J Dent Educ. 2009;73(12):1379-86.

21- Moore PA, Nahouraii HS, Zovko JG, Wisniewski SR. Dental therapeutic practice patterns in the U.S. I. Anesthesia and sedation. Gen Dent. 2006;54(2):92-8.

22- American Dental Association. Guidelines for teaching pain control and sedation to dentists and dental students, as adopted by the October 2007 ADA House of Delegates. www.ada.org/prof/resources/positions/statements/anxiety guidelines.pdf

Copyright (C) 2014 The Author(s); This is an open-access article distributed under the terms of the Creative Commons Attribution License (http://creativecommons.org/licenses/by/4.0), which permits unrestricted use, distribution, and reproduction in any medium, provided the original work is properly cited. 